\title{
A Study on Optimization of Process Parameters in Machining of Bronze using Wire-EDM
}

\author{
Gajanan Kamble $^{* 1}$, Dr. N. Lakshamanaswamy ${ }^{2}$, Gangadhara H S ${ }^{3}$, Sharon Markus ${ }^{4}$, N. Rajath ${ }^{5}$ \\ ${ }^{1}$ PG Scholar, Department of Mechanical Engineering, University Visvesvaraya College of Engineering, Bangalore, \\ India \\ ${ }^{2}$ Professor and Former Chairman, Department of Mechanical Engineering, University Visvesvaraya College of \\ Engineering, Bangalore, India \\ ${ }^{3}$ PG Scholar, Department of Mechanical Engineering, University Visvesvaraya College of Engineering, Bangalore, \\ India \\ ${ }^{4}$ PG Scholar, Department of Mechanical Engineering, East West Institute of technology, Bangalore, India \\ ${ }^{5}$ PG Scholar, Department of Mechanical Engineering, B.M.S College of Engineering, Bangalore, India
}

\begin{tabular}{|c|c|}
\hline & ABSTRACT \\
\hline $\begin{array}{l}\text { Article Info } \\
\text { Volume8, Issue } 5 \\
\text { Page Number:484-493 } \\
\text { Publication Issue } \\
\text { September-October-2021 } \\
\text { Article History } \\
\text { Accepted :16Oct2021 } \\
\text { Published :30Oct2021 }\end{array}$ & $\begin{array}{l}\text { Wire cut electrical discharge machining (WEDM) is a hybrid manufacturing } \\
\text { technology which enables machining of all engineering materials. This research } \\
\text { article deals with investigation on Optimization of the Process Parameters of the } \\
\text { wire cut EDM of Bronze material of dimension }(80 * 80 * 40) \text { in mm. Material } \\
\text { removal rate, Surface roughness and Kerf width were studied against the process } \\
\text { parameters such as Pulse on time(TON), Pulse off time (TOFF) and Current(IP). } \\
\text { The machining parameters for wire EDM were optimized for achieving the } \\
\text { combined objectives. As there are three input parameters } 27 \text { experiments is carried } \\
\text { out and full factorial is used. Optimized parameters were found using (ANOVA) } \\
\text { and the error percentage can be validated and parameter contribution for the } \\
\text { Material Removal Rate (MRR) and Surface roughness were found. } \\
\text { Keywords: Wire EDM (Electrical Discharge Machining), Bronze, ANOVA } \\
\text { (Analysis of Variance) }\end{array}$ \\
\hline
\end{tabular}

\section{INTRODUCTION}

Mechanical Industries aims at quality and time with respect to efficiency of the product, demand, competence and global acceptance as well. It also conveys the necessity in using complicated parts and precise components which are having good dimensional tolerances with special shapes. The demand and need for temperature resistant, hard, tough, wear, corrosion and abrasive resistant materials are increasing day by day. These increasing trends needs have enforced on the usage of advanced and well-equipped technologies to convert the raw materials into finished products with low cost and time required for the operations such as tooling.

The traditional machining processes, in spite of recent advancements, fails to machine difficult to machine components in high strength, high temperature, hard and die steels as well. Considering these scenarios into account, a number of an conventional machining processes have been discovered and developed. Unconventional machining methods such as Ultrasonic machining, electrochemical machining, electrical discharging machine (EDM) can be applied in machining of components which are difficult to machine. The non-traditional machining methods exhibit few unique advantages over conventional 
techniques which are not restricted by any mechanical properties such as toughness, brittleness and hardness. It ensures good surface finish on any intricate components by excellent control over physical parameters. Since the conventional methods are not suitable for machining hard materials, non-traditional machines are used which are feasible, economical too. There are some characteristics listed below which provides the limitations of conventional techniques.

Removal of the metal in the form of chips is a difficult procedure.

1. Chips are usually unwanted in the process of metal removal.

2. Chips removal and the disposal of the chips are tedious, involves the wastage of energy and money.

3. Since the presence of larger cutting forces, it is difficult to hold the work piece properly. Proper holding of the work piece also avoids distortion.

4. Due to the excess amount of heat is generated at the interface of tool and work piece; there will be some undesirable effects which diminishes the properties.

Developing these non-traditional methods encourages the machining of complex shaped dies and moulds in hard and high temperature resistant alloys for example titanium alloys, carbides, heat resistant steels etc. These non-traditional machined components have greater applications in the fields of nuclear engineering and aerospace industries

New advanced/ technological processes are divided into different categories.

(a) Type of energy (Shaping of materials)-thermal, Mechanical, Electro thermal and Electro chemical;

(b)The process involves some basic mechanisms such as ionic dissolution, erosion and vaporization;

(c) Energy sources required in removal of materialhigh current density, hydrostatic pressure, ionized material, high voltage.

(d)Transferring of energies in a particular medium electrolyte, Electron, hot gases and high velocity particles.

\section{METHODS AND MATERIAL}

\section{Material preparation}

The work piece material used for the experimental analysis is bronze with dimensions of $80 \mathrm{~mm} * 80 \mathrm{~mm} * 40 \mathrm{~mm}$. The work piece is initially surface cleaned before conducting the experiments. The molybdenum wire with diameter $0.18 \mathrm{~mm}$ is used as electrode. The machining accuracy is $0.01 \mathrm{~mm}$. DK 7732 CONCORD wire EDM Machine is used for the experimentation.

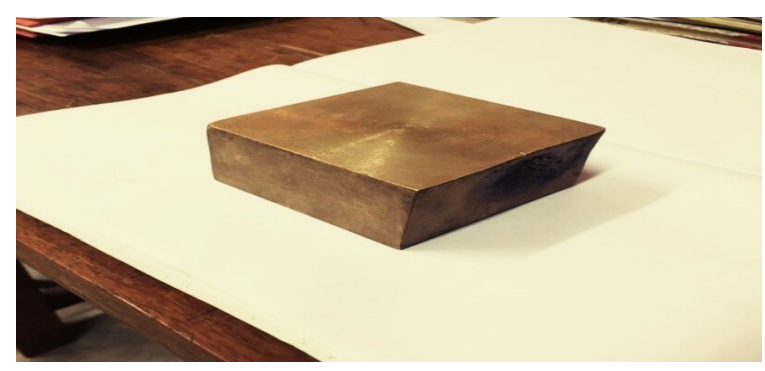

Figure 1.Bronze Material used for experimentation

\section{Preliminary experimentation:}

Three parameters were chosen, namely Pulse On, Pulse Off and Current. These parameters were varied simultaneously so as to obtain the minima and maxima of the chosen set of parameters. The response variable considered in this regard was material removal rate and wire strength. As the material removal rate was increased, probability of snipping of wire increased. The maximum MRR was achieved keeping in mind the wire life.

\begin{tabular}{|l|l|c|c|c|}
\hline Sl No. & Parameter & $\begin{array}{l}\text { Pulse on } \\
(\mu \mathrm{s})\end{array}$ & $\begin{array}{l}\text { Pulse } \\
\text { Off }(\mu \mathrm{s})\end{array}$ & $\begin{array}{l}\text { Current }( \\
\mathrm{A})\end{array}$ \\
\hline $\begin{array}{l}\text { Material } \\
\text { Removal } \\
\text { Rate }\end{array}$ & Maximum & 35 & 10 & 5 \\
\cline { 2 - 5 } & Minimum & 25 & 8 & 3 \\
\hline
\end{tabular}

\section{Equipment used for Experimentation}

DK 7732 CONCORD Wire EDM Machine is used for the experimentation; molybdenum wire is used for the experimentation. Once the wire is wound on the wire drum, that particular amount of Wire will be used for all the experiments and it can be replaced once the material is changed. Work material will be clamped tightly on the work table so as to avoid any relative motion between work piece and the wire. Dielectric flow is constant during the experiment. 


\section{Experimental Design (Input parameters)}

\begin{tabular}{|l|l|l|l|l|l|}
\hline $\begin{array}{l}\text { S1. } \\
\text { no }\end{array}$ & $\begin{array}{l}\text { Process } \\
\text { parameters }\end{array}$ & Unit & Level1 & Level2 & Level3 \\
\hline 1 & $\begin{array}{l}\text { Pulse } \\
\text { ontime(T } \\
\text { on) }\end{array}$ & Hs & 25 & 30 & 35 \\
\hline 2 & $\begin{array}{l}\text { Pulse } \\
\text { offtime(T } \\
\text { off) }\end{array}$ & Hs & 8 & 9 & 10 \\
\hline 3 & Current(Ip) & A & 3 & 4 & 5 \\
\hline
\end{tabular}

The experimental design was according to Full factorial. Table shows the process parameters with their level consider for this experimentation.

1. The Bronze material is clamped tightly so that there is no movement of work piece material during machining.

2. The Molybdenum wire is wound on the wire drum which is brought near the material during machining.

3. The table movement should be adjusted so that the wire comes in contact with the work piece.

4. The values of input parameters are fed to computer which is in connected to the Wire Cut EDM machine.

5. The electric discharge is produced and dielectric fluid is sprayed on the bronze material.

6. The machining of the bronze material takes place and output parameters can be calculated.

Figure.2 Wire Electrical Discharge Machine

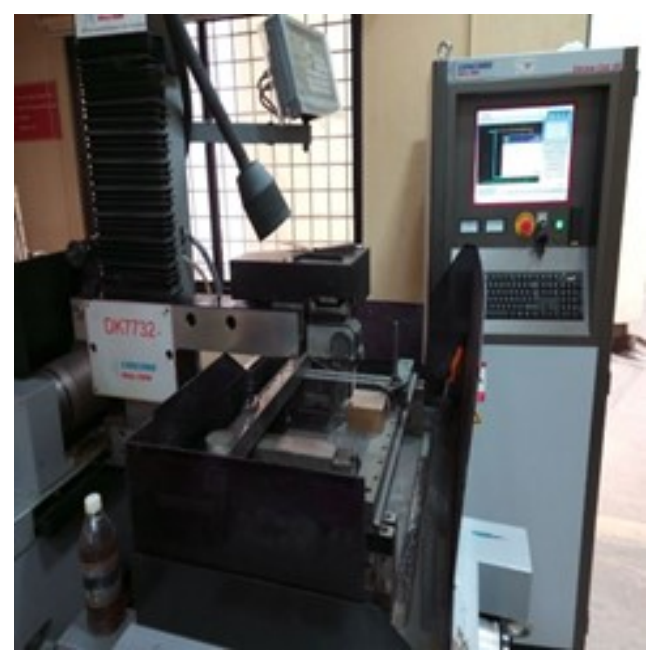

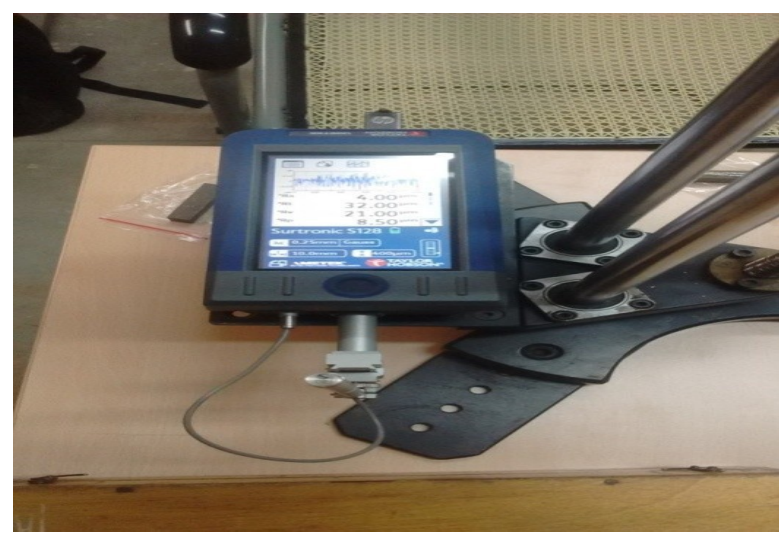

Figure3 Surface Roughness tester

The measurement of Surface Roughness was done using Taylore Hobbson Surtronic device. The reason for using this device is that they are tough, fast and reliable testers. The device used is user friendly. Surtronic series stand and primer the integrated roughness measurement station can be obtained. Roughness measurements can be easily done and on multiple parts and results can be stored internally or in a standard USB device.

Durable roughness testers are used for shop floor, industrial and inspection room applications.

\section{METHODOLOGY Analysis of Variance (ANOVA)}

ANOVA is a standard statistical technique which is used to interpret the experimental results. The percentage contribution of various process parameters to the selected performance characteristic can also be estimated by ANOVA technique. Thus, information about how significant the effect of each controlled parameter is on the quality characteristic of interest can be obtained. ANOVA for raw data has been done to identify the important parameters and to quantify their effect on the performance characteristic. The ANOVA based on the raw data helps to identify the factors which affect average response rather than reducing variation.

ANOVA is used in testing and significance of all the main factors and interactions and mean square values and experimental errors at specific confidence level. Study of ANOVA table helps to determine the factors which needs controls and which factors do not need control. The confirmation experiment is done to determine the optimum conditions. The analysis of partial experiment consists of analysis of Confidence which can be shown in the results. 


\section{RESULTS AND DISCUSSION}

Inputandoutput parametervalues

\begin{tabular}{|c|c|c|c|c|c|c|c|c|c|c|c|c|}
\hline Expt.No. & Pulse0N & Pulse0FF & Current & Wb & Wa & Wb-Wa & Time & MRR & $\mathbf{R a}$ & KwT & KwB & kwT-KwB \\
\hline 1 & 25 & 8 & 3 & 2.420 & 2.385 & 0.035 & 28.14 & 0.0012438 & 3.70 & 10.03 & 10.02 & 0.01 \\
\hline 2 & 25 & 8 & 4 & 2.385 & 2.344 & 0.041 & 22.01 & 0.0018628 & 4.40 & 10.03 & 10.01 & 0.02 \\
\hline 3 & 25 & 8 & 5 & 2.344 & 2.303 & 0.041 & 18.19 & 0.0022540 & 4.30 & 10.03 & 10.02 & 0.01 \\
\hline 4 & 25 & 9 & 3 & 2.303 & 2.262 & 0.041 & 28.03 & 0.0014627 & 3.40 & 10.02 & 10.01 & 0.01 \\
\hline 5 & 25 & 9 & 4 & 2.262 & 2.222 & 0.040 & 22.40 & 0.0017857 & 4.10 & 10.01 & 9.99 & 0.02 \\
\hline 6 & 25 & 9 & 5 & 2.222 & 2.180 & 0.042 & 18.34 & 0.0022901 & 4.00 & 10.00 & 9.99 & 0.01 \\
\hline 7 & 25 & 10 & 3 & 2.180 & 2.137 & 0.043 & 30.08 & 0.0014295 & 3.40 & 10.01 & 10.00 & 0.01 \\
\hline 8 & 25 & 10 & 4 & 2.137 & 2.095 & 0.042 & 23.05 & 0.0018221 & 4.00 & 10.04 & 10.02 & 0.02 \\
\hline 9 & 25 & 10 & 5 & 2.095 & 2.049 & 0.046 & 20.55 & 0.0022384 & 4.30 & 10.05 & 10.03 & 0.02 \\
\hline 10 & 30 & 8 & 3 & 2.049 & 2.014 & 0.035 & 26.09 & 0.0013415 & 3.60 & 10.04 & 10.00 & 0.04 \\
\hline 11 & 30 & 8 & 4 & 2.014 & 1.972 & 0.042 & 19.37 & 0.0021683 & 3.60 & 9.97 & 9.94 & 0.03 \\
\hline 12 & 30 & 8 & 5 & 1.972 & 1.931 & 0.041 & 16.42 & 0.0024970 & 4.50 & 10.02 & 10.01 & 0.01 \\
\hline 13 & 30 & 9 & 3 & 1.931 & 1.891 & 0.040 & 26.30 & 0.0015209 & 4.70 & 10.00 & 9.99 & 0.01 \\
\hline 14 & 30 & 9 & 4 & 1.891 & 1.850 & 0.041 & 21.13 & 0.0019404 & 4.50 & 10.00 & 9.99 & 0.01 \\
\hline 15 & 30 & 9 & 5 & 1.850 & 1.810 & 0.040 & 18.52 & 0.0021598 & 4.20 & 10.03 & 10.02 & 0.01 \\
\hline 16 & 30 & 10 & 3 & 1.810 & 1.768 & 0.042 & 30.05 & 0.0013977 & 4.30 & 10.05 & 10.03 & 0.02 \\
\hline 17 & 30 & 10 & 4 & 1.768 & 1.725 & 0.043 & 24.09 & 0.0017850 & 4.90 & 10.03 & 10.02 & 0.01 \\
\hline 18 & 30 & 10 & 5 & 1.725 & 1.679 & 0.046 & 20.41 & 0.0022538 & 3.90 & 10.03 & 10.02 & 0.01 \\
\hline 19 & 35 & 8 & 3 & 1.679 & 1.638 & 0.041 & 25.50 & 0.0016078 & 4.90 & 10.04 & 10.03 & 0.01 \\
\hline 20 & 35 & 8 & 4 & 1.638 & 1.598 & 0.040 & 19.46 & 0.0020555 & 4.70 & 10.03 & 10.01 & 0.02 \\
\hline 21 & 35 & 8 & 5 & 1.598 & 1.561 & 0.037 & 17.01 & 0.0021752 & 4.30 & 10.04 & 10.02 & 0.02 \\
\hline 22 & 35 & 9 & 3 & 1.561 & 1.521 & 0.040 & 28.02 & 0.0014276 & 4.00 & 10.00 & 9.98 & 0.02 \\
\hline 23 & 35 & 9 & 4 & 1.521 & 1.482 & 0.039 & 22.25 & 0.0017528 & 4.50 & 10.02 & 10.00 & 0.02 \\
\hline 24 & 35 & 9 & 5 & 1.482 & 1.444 & 0.038 & 19.07 & 0.0019927 & 4.50 & 10.03 & 10.01 & 0.02 \\
\hline 25 & 35 & 10 & 3 & 1.444 & 1.402 & 0.042 & 31.01 & 0.0013544 & 4.20 & 10.00 & 9.98 & 0.02 \\
\hline 26 & 35 & 10 & 4 & 1.402 & 1.361 & 0.041 & 24.46 & 0.0016762 & 4.70 & 10.01 & 9.99 & 0.02 \\
\hline 27 & 35 & 10 & 5 & 1.361 & 1.321 & 0.040 & 21.03 & 0.0019020 & 4.60 & 10.02 & 10.01 & 0.01 \\
\hline
\end{tabular}

\section{EFFECT OF PROCESS PARAMETERS ON MRR}

\section{Effect of PulseONTimeon MRR}

The figure 4. shows the relationship between Pulse on Time and MRR. This may be due to reason that with high pulse on time, more material gets melted at the tool work piece interface, which require proper flushing time but as the value of pulse off time is too short, so there is not enough time for the flushing to clear the debris from the inter-electrode gap between the tool and work piece, so arcing take place which result in decreasing the MRR.

\section{Effect of Pulse OFF Time on MRR}

There is a decrease in the MRR with an increase in the Pulse Off Time. MRR and Pulse Off Time are inversely related. The MRR decreases with lesser amplitude of Variations from 8to10 as shown in figure 4. This is because number of discharges within the desired period of time becomes smaller due to the time between two pulses which leads to lower cutting speed. 
Also, there may be due to reduction in melting rate and spark ignition ratio in the plasma channel which causes lower MRR.

\section{Effect of Peak Current on MRR}

Figure 4 shows the significant increase in MRR with increase in peak current. This is because of the fact that with increase in the value of peak current, the energy/discharges get enhances which leads to wards increase in the cutting speed and material removal rate.

\section{Regression Equation}

MRR $=0.001185-0.000011$ Pulse on $-\mathbf{0 . 0 0 0 0 7 7}$

Pulse off + 0.000419 Current

\begin{tabular}{|c|c|c|c|c|}
\hline Expt No. & Pullse ON & Pulse OrF & Curreut & IIRR \\
\hline$T$ & 25 & 8 & 3 & 0.0012438 \\
\hline 2 & 25 & 8 & 1 & 0.018028 \\
\hline 3 & 25 & 8 & 5 & 0.002540 \\
\hline 4 & 25 & 9 & 3 & 0.014027 \\
\hline 5 & 25 & 9 & 4 & 0.017857 \\
\hline 6 & 25 & 9 & 5 & 0,0022901 \\
\hline 7 & 25 & 10 & 3 & 0.0014295 \\
\hline 8 & 25 & 10 & 4 & 0,0018221 \\
\hline 9 & 25 & 10 & 5 & 0.0022384 \\
\hline 10 & 30 & 8 & 3 & 0.0015415 \\
\hline II & 30 & 8 & 4 & 0.001683 \\
\hline 12 & 30 & 8 & 5 & 0.0024970 \\
\hline 13 & 30 & 9 & 3 & 0.0015209 \\
\hline 14 & 30 & 9 & 4 & 0.0019404 \\
\hline 15 & 30 & 9 & 5 & 0.001598 \\
\hline 16 & 30 & 10 & 3 & 0.013977 \\
\hline 17 & 30 & 10 & 4 & 0.0017850 \\
\hline 10 & 30 & 10 & 5 & 0.0022530 \\
\hline 19 & 35 & 8 & 3 & 0.0016078 \\
\hline 20 & 35 & 8 & 4 & 0,0020555 \\
\hline 21 & 35 & 8 & 5 & 0.001752 \\
\hline 22 & 35 & 9 & 3 & 0,014276 \\
\hline 23 & 35 & 9 & 4 & 0.0017528 \\
\hline 24 & 35 & 9 & 5 & 0.019927 \\
\hline 25 & 35 & 10 & 3 & 0.0013544 \\
\hline 26 & 35 & 10 & 4 & 0,016762 \\
\hline 27 & 35 & 10 & 5 & 0.0019020 \\
\hline
\end{tabular}

Figure4 Main Effects plot for Material removal rate
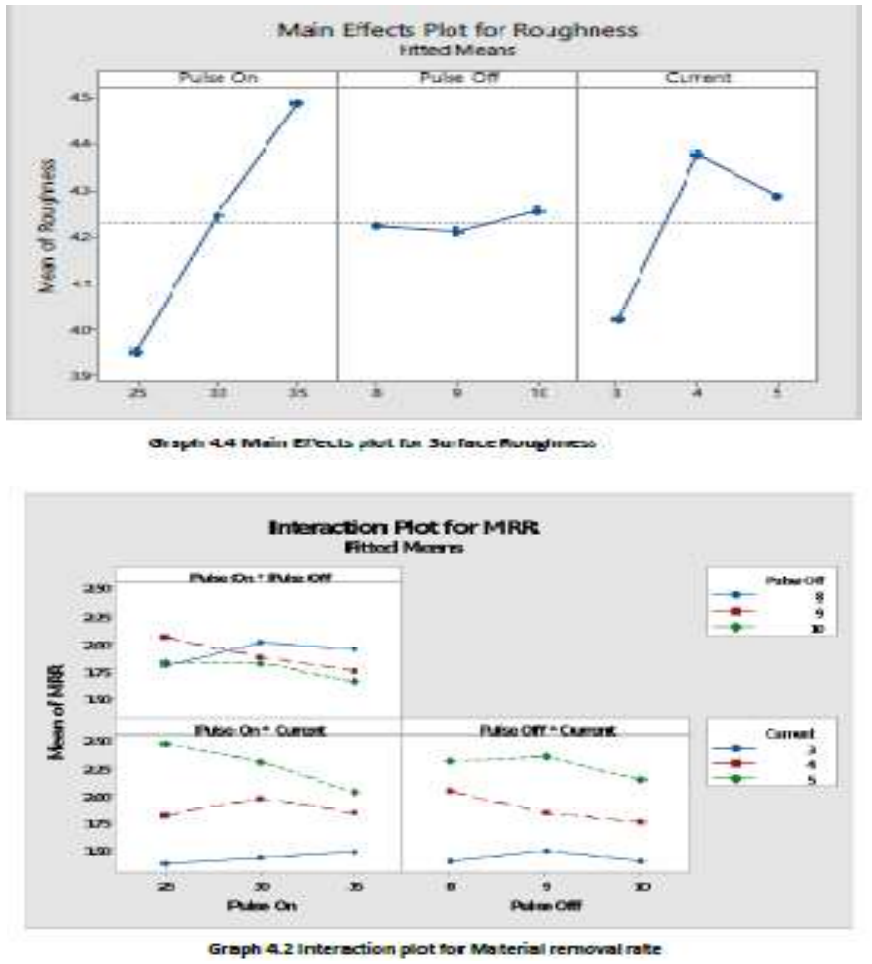

\section{Surface Roughness}

\begin{tabular}{|c|c|c|c|c|}
\hline $\begin{array}{l}\text { Erpt. } \\
\text { No. }\end{array}$ & $\begin{array}{l}\text { Pulse } \\
\text { ON }\end{array}$ & $\begin{array}{l}\text { Palse } \\
\text { OFF }\end{array}$ & $\begin{array}{c}\text { Peak } \\
\text { Current }\end{array}$ & $\begin{array}{c}\text { Ra } \\
\text { Value }\end{array}$ \\
\hline I & 25 & 8 & 3 & 3.70 \\
\hline 2 & 25 & 8 & 4 & 4.40 \\
\hline 3 & 25 & 8 & 5 & 4.30 \\
\hline 4 & 25 & 9 & 3 & 3.40 \\
\hline 5 & 25 & 9 & 4 & 4.10 \\
\hline 6 & 25 & 9 & 5 & 4.00 \\
\hline 7 & 25 & 10 & 3 & 3.10 \\
\hline 8 & 25 & 10 & 4 & 4.00 \\
\hline 9 & 25 & 10 & 5 & 430 \\
\hline 10 & 30 & 8 & 3 & 3.60 \\
\hline 11 & 30 & 8 & 4 & 3.60 \\
\hline 12 & 30 & 8 & 5 & 4.50 \\
\hline 13 & 30 & 9 & 3 & 4.70 \\
\hline 14 & 30 & 9 & 4 & 4.50 \\
\hline 15 & 30 & 9 & 5 & 420 \\
\hline 15 & 30 & 10 & 3 & 430 \\
\hline 17 & 30 & 10 & 4 & 4.90 \\
\hline 18 & 30 & 10 & 5 & 390 \\
\hline 19 & 35 & 8 & 3 & 490 \\
\hline 20 & 35 & $\mathrm{~s}$ & 4 & 4.00 \\
\hline 21 & 35 & 8 & 5 & 430 \\
\hline 22 & 35 & 9 & 3 & 4.00 \\
\hline 23 & 35 & 9 & 4 & 4.50 \\
\hline 24 & 35 & 9 & 5 & 4.50 \\
\hline 75 & 75 & 10 & 7 & 430 \\
\hline 26 & 35 & 10 & 4 & 470 \\
\hline 27 & 35 & 10 & 5 & 4.60 \\
\hline
\end{tabular}




\section{The figure4.4 shows the Main effects plots for Surface Roughness.}

1. As the pulse on time increases from 25 to 35 , the mean of Surface Roughness increases gradually. The increase in surface roughness was observed with increased pulse on time. This is because of increased pulse on time which produces larger discharge energy between electrode and the work piece. It ceases to melt more amounts of Material which helps to create a larger and deeper crater.

2. As the pulse off time increases from 8 to 10 , the mean of roughness remains constant from 8 to 9 and increases from 9 to 10 . As the increase in pulse off time, there were no changes in the surface rough nesses during machining of bronze material. This is due to the time between the pulse width which is in consequentially increased and which is not much affecting the ratio of pulse energy in the plasma channel between the electrode and work piece surface.

3. As the current increases from 3 to5, the mean of surface roughness increases from 3 to 4 but decreases gradually from 4 to5. The mean of surface roughness increases from 3 to 4 due to the presence of larger discharge energy as the current is increased and form 4 to 5 the melting of material and large and deeper crater decreases the surface roughness.

\section{Regression Equation $=1.95+0.0533$ Pulse on +0.0167 Pulse off +0.1333 Current}

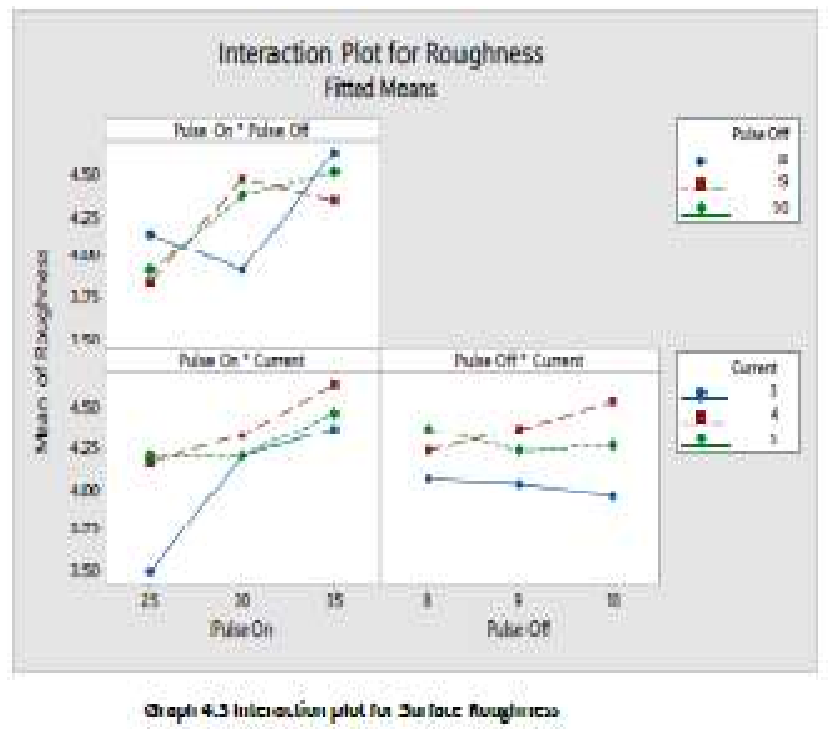

Figure4.4MainEffectsplotforSurfaceRoughness

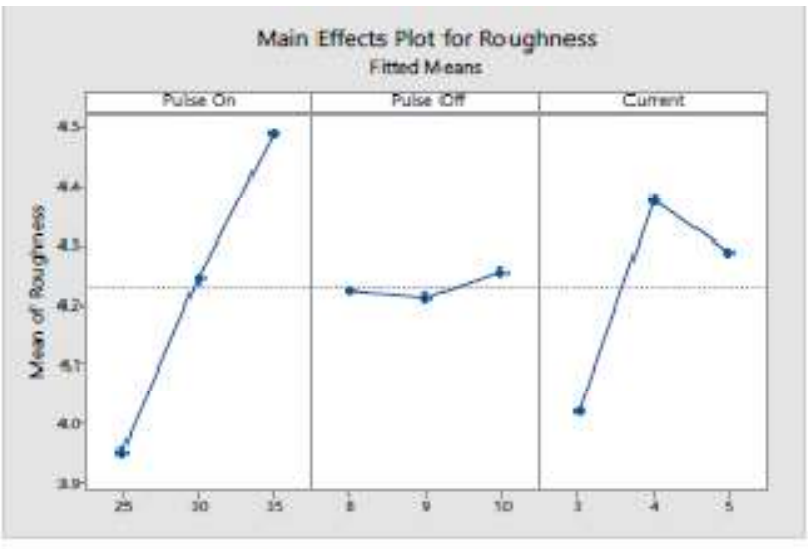

Graph 4.4 Msin Effects plot for Surtace Roughness

Table 4.3 statistical and Experimental values of MRR and surface roughness

\begin{tabular}{|c|c|c|c|c|c|c|}
\hline \multirow[b]{2}{*}{$\begin{array}{l}\text { Pulse } \\
\text { on }\end{array}$} & \multirow[b]{2}{*}{$\begin{array}{c}\text { Pulse } \\
\text { off }\end{array}$} & \multirow[b]{2}{*}{ Current } & \multicolumn{2}{|c|}{ Experimental values } & \multicolumn{2}{|c|}{ Statistical values } \\
\hline & & & $\begin{array}{l}\text { Surface } \\
\text { roughness }\end{array}$ & MRR & $\begin{array}{c}\text { Surface } \\
\text { roughness }\end{array}$ & MIRR \\
\hline 25 & 8 & 3 & 3.7 & 0.001243 & 3.816 & 0.001551 \\
\hline 25 & 8 & 4 & 4.4 & 0.001862 & 39493 & 0.00197 \\
\hline 25 & 8 & 5 & 4.3 & 0.002253 & 4.0826 & 0.002389 \\
\hline 25 & 9 & 3 & 3.4 & 0.001462 & 3.8327 & 0.001474 \\
\hline 25 & 9 & 4 & 4.1 & 0.001785 & 3.956 & 0.001893 \\
\hline 25 & 9 & 5 & 4 & 0.0029 & 40993 & 0.002312 \\
\hline 25 & 10 & 3 & 3.4 & 0.001425 & 3.8494 & 0.001397 \\
\hline 25 & 10 & 4 & 4 & 0.001782 & 39827 & 0.001816 \\
\hline 25 & 10 & 5 & 4.3 & 0.002238 & 4.116 & 0.002235 \\
\hline 30 & 8 & 3 & 3.6 & 0.001341 & 40825 & 0.001496 \\
\hline 30 & 8 & 4 & 3.6 & 0.002168 & 4.2158 & 0.001915 \\
\hline 30 & 8 & 5 & 45 & 0.00249 & 43491 & 0.002334 \\
\hline 30 & 9 & 3 & 4.7 & 0.00152 & 4.0992 & 0.001419 \\
\hline 30 & 9 & 4 & 4.5 & 0.00194 & 4.2325 & 0.001838 \\
\hline 30 & 9 & 5 & 4.2 & 0.002159 & 4.3658 & 0.002257 \\
\hline 30 & 10 & 3 & 43 & 0.001397 & 41159 & 0.001342 \\
\hline 30 & 10 & 4 & 49 & 0.001784 & 4.2492 & 0.001761 \\
\hline 30 & 10 & 5 & 39 & 0.002253 & 4.3825 & 0.00218 \\
\hline 35 & 8 & 3 & 49 & 0.001607 & 4349 & 0.001441 \\
\hline 35 & 8 & 4 & 4.7 & 0.002055 & 4.4823 & 0.00186 \\
\hline 35 & 8 & 5 & 43 & 0.002175 & 4.6156 & 0.002279 \\
\hline 35 & 9 & 3 & 4 & 0.001475 & 43657 & 0.001364 \\
\hline 35 & 9 & 4 & 4.5 & 0.00176 & 4.499 & 0.001783 \\
\hline 35 & 9 & 5 & 45 & 0.0019926 & 46323 & 0.002202 \\
\hline 35 & 10 & 3 & 4.2 & 0.0013544 & 4.3824 & 0.001287 \\
\hline 35 & 10 & 4 & 47 & & 57 & \\
\hline
\end{tabular}

The statistical and experimental values are shown in the table. The experimental values formetal removal rate and surface roughness are shown in the table. The statistical values are obtained by substituting the values of input parameters in the regression equation.

\section{Regression Equation}

MRR=0.001185-0.000011 Pulse on- 0.000077 Pulse off + 0.000419 Current

\section{Regression Equation}

Sur Rou $=1.95+0.0533$ Pulse on +0.0167 Pulse off +0.1333 Current 
The graph 4.5 shows the interaction plots for Kerf width

The graph 4.6 shows the main effect plots for Kerf width

1. As the pulse on time increases from 25 to 35 , the Kerf width also increases. This because unevenly distribution of sparks and the discharge energy also decreases so the pulse on time increases.

\begin{tabular}{|c|c|c|c|c|c|c|}
\hline Ext. No. & Palse ON & $\begin{array}{l}\text { Pulse } \\
\text { OFF }\end{array}$ & Current & KwT & KwB & $\begin{array}{l}\text { LwT- } \\
\text { KwB }\end{array}$ \\
\hline 1 & 25 & 8 & 3 & 10.03 & 1002 & 0.01 \\
\hline 2 & 25 & 8 & 4 & 10.03 & 1001 & 0.02 \\
\hline 3 & 25 & 8 & 5 & 10.03 & 1002 & 0.01 \\
\hline 4 & 25 & 9 & 3 & 10.02 & 1001 & 0.01 \\
\hline 5 & 25 & 9 & 4 & 10.01 & 999 & 0.02 \\
\hline 6 & 25 & 9 & 5 & 10.00 & 999 & 0.01 \\
\hline 7 & 25 & 10 & 3 & 10.01 & 10.00 & 0.01 \\
\hline 8 & 25 & 10 & 4 & 10.04 & 10.02 & 0.02 \\
\hline 9 & 25 & 10 & 5 & 10.05 & 10.03 & 0.02 \\
\hline 10 & 30 & 8 & 3 & 10.04 & 10.00 & 0.04 \\
\hline II & 30 & 8 & 4 & 997 & 994 & 0.03 \\
\hline 12 & 30 & 8 & 5 & 10.02 & 10.01 & 0.01 \\
\hline 15 & 30 & 9 & 3 & 70.00 & 999 & 0.01 \\
\hline 14 & 30 & 9 & 4 & 10.00 & 999 & 0.01 \\
\hline 15 & 30 & 9 & 5 & 10.03 & 10.02 & 0.01 \\
\hline 16 & 30 & 10 & 3 & 10.05 & 10.03 & 0.02 \\
\hline 17 & 30 & 10 & 4 & 10.03 & 1002 & 0.01 \\
\hline 18 & 30 & 10 & 5 & 10.03 & 10.02 & 0.01 \\
\hline 19 & 35 & 8 & 3 & 10.04 & 10.03 & 0.01 \\
\hline 20 & 35 & 8 & 4 & 10.03 & 10.01 & 0.02 \\
\hline 21 & 35 & 8 & 5 & 10.04 & 1002 & 0.02 \\
\hline 22 & 35 & 9 & 3 & 10.00 & 908 & 0.02 \\
\hline 23 & 35 & 9 & 4 & 10.02 & 1000 & 0.02 \\
\hline 24 & 35 & 9 & 5 & 10.03 & 1001 & 002 \\
\hline 25 & 35 & 10 & 3 & 10.00 & 998 & 0.02 \\
\hline 26 & 35 & 10 & 4 & 10.01 & 9.99 & 0.02 \\
\hline 27 & 35 & 10 & 5 & 10.02 & 10.01 & $00 !$ \\
\hline
\end{tabular}

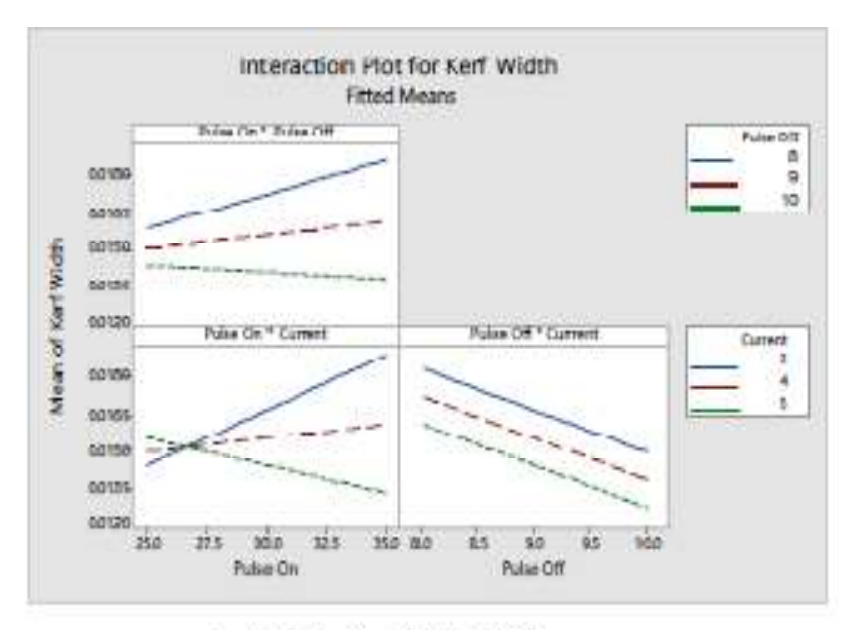

Graph 4.5 intersction plot for Kerr witth

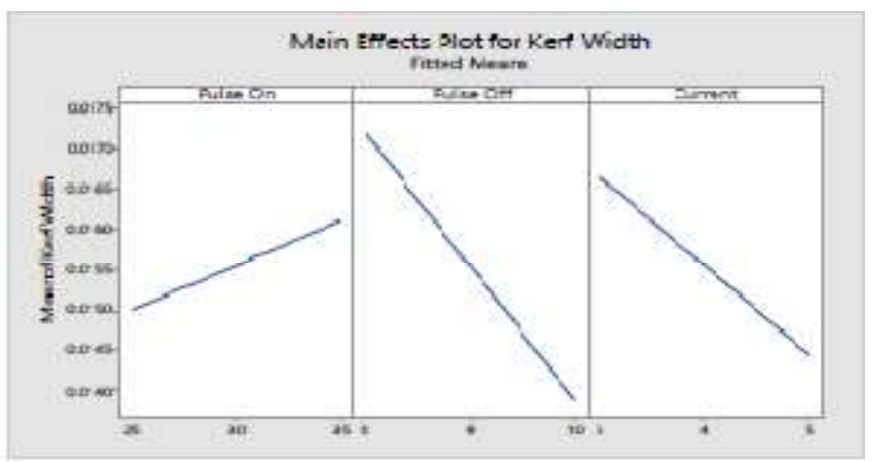

Grash 46 Mein Etects plot for Kert wieth

2.As the pulse off time increases from 8to10, the Kerf width decreases gradually. The reason for decrease in Kerf width is with the decrease of discharge duration, the overcut during discharge also increases as the discharge energy per pulse increases.

3. As the current increases from 3 to 5 , the Kerf width decreases gradually. The main reason behind this is that higher the peak current, higher will be the spark energy. This high spark energy produces larger amount of debris. The debris sticks on the work piece trap and may cause unwanted spark. The unwanted sparks result in tool material erosion, which results in less material removal, as the significant amount of spark energy is used in sparking With debris, leading to less Kerf width.

\section{EDS (Energy dispersive X-ray spectrometry)}

EDS makes use of the X-rays emitted when a beam of electrons hits the sample. This provides the information regarding the chemical composition present in the sample. In this project chemical composition is checked for Bronze Material. The major principal elements present in the bronze material are copper with $69.37 \%$. The other elements like zinc, lead, carbon and tin are present in the small percentages.

The graph shows the higher peaks of copper which means copper is present in higher percentage which is indicated in the table as $69.37 \%$. The other elements like Zinc(3.54), Tin(1.82), lead (14.4) and carbon (10.88) are present in small percentages which is indicated by small peaks in the graph. 


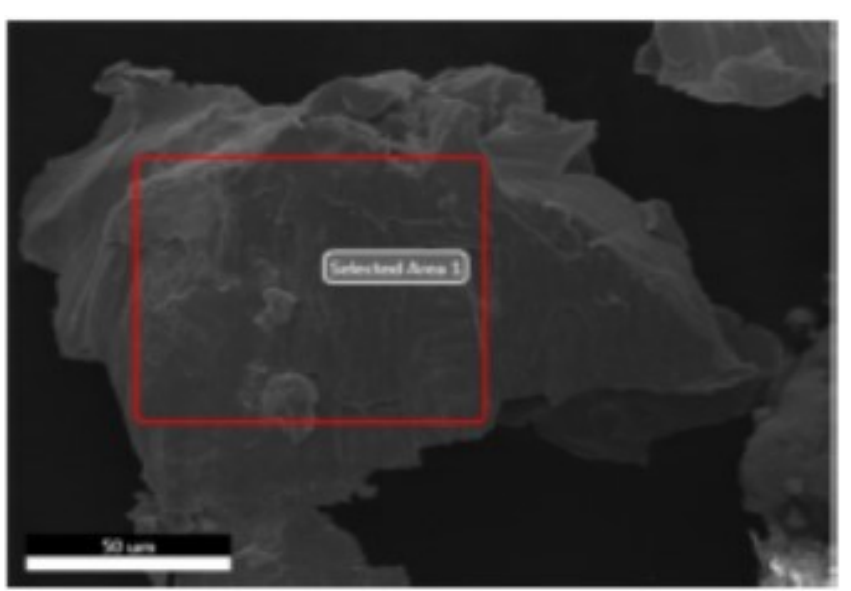

Figure 4.7 Selected area of Bronze material

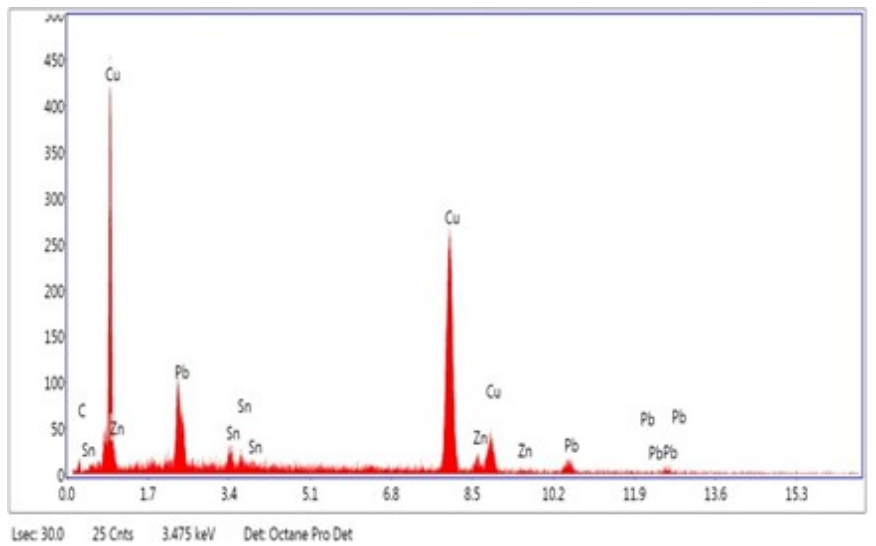

Figure 4.8 Composition of Bronze material

\section{CONCLUSION}

Experimental investigation on wire electrical discharge machining of Bronze has been done using Molybdenum wire of $0.18 \mathrm{~mm}$. The performance parameters included pulse on time(Ton), Pulse off time (Toff), Current(Ip). Experiments were conducted according to L27 Orthogonal Array Design. The optimum parameters value combination was found which would yield minimum Surface Roughness (SR) and Maximum Material Removal Rate(MRR).

\section{The following conclusions are made.}

1.The main significant factor which affects the Material removal rate is Current.

2.Pulse ON time and Pulse OFF time has least significant effect on material removal rate.
3.The two significant factors which affects surface roughness is Pulse ON time and Current.

4.The Pulse OFF time has negligible influence on surface roughness.

5. The Material removal rate is found to be maximum at Pulse ON Time-30, Pulse OFF Time10, Current-5.

6. The surface roughness was found be minimum at Pulse ON Time-25, Pulse OFF Time-9, Current-3.

7.EDS (Energy dispersive X-ray spectrometry) analysis was done on the Bronze sample.

8. Kerf width increases with increase in Pulse ON time, Pulse OFF and current decreases with increase in Kerf width values.

\section{REFERENCES}

[1]. Atul Kumar and Dr. D. K. Singh, 2012. "Performance Analysis of Wire Electric Discharge Machining (W-EDM)." International Journal of Engineering Research \& Technology (IJERT) Vol. 1 Issue 4, June - 2012, ISSN: 22780181.

[2]. Pujari Srinivasa Rao, Koona Ramji, Beela Satyanarayana. "Effect of WEDM Conditions on Surface Roughness: A Parametric Optimization Using Taguchi Method.” IJAEST, Volume No. 6, Issue No. 1, pp. 041 - 048.

[3]. Saurav Datta, Siba Sankar Mahapatra. "Modelling Simulation and Parametric Optimization of Wire EDM Process Using Response Surface Methodology 111 Coupled with Grey- Taguchi Technique." International Journal of Engineering, Science and Technology. Vol. 2, No. 5, 2010, pp. 162-183.

[4]. Nihat Tosun, Can Cogun and Gul Tosun, 2004. "A Study on Kerf and Material Removal Rate in Wire Electrical Discharge Machining Based on Taguchi Method." Journal of Materials Processing Technology 152 (2004) 316-322.

[5]. Mustafa I'lhanGokler, Alp MithatOzano"zgu, 2000. "Experimental Investigation of Effects of Cutting Parameters on Surface Roughness in The 
WEDM Process." International Journal of Machine Tools \& Manufacture 40 (2000) 18311848.

[6]. Chiang, K.T., Chang, F.P, "Optimization of the WEDM process of particle reinforced material with multiple performance characteristics using grey relational analysis", Journal of Materials Processing Technology, 180, 96-101. (2006).

[7]. C.D.Shah, J.R.Mevada and B.C.Khatri, "Optimization of Process Parameter of Wire Electrical Discharge Machine by Response Surface Methodology on Inconel600", International Journal of Emerging Technology and Advanced Engineering, volume 3, issue 4, April (2013)

[8]. Kamal Jangra, Sandeep Grover and Aman Aggarwal "Simultaneous Optimization of Material Removal Rate and Surface Roughness for WEDM of WC-Co Composite Using Grey Relational Analysis Along with Taguchi Method" International Journal of Industrial Engineering Computations 2 (2011) 479-490.

[9]. Ahmet Hasçalýk and UlasÇaydas "Experimental study of wire electrical discharge machining of AISI D5 tool steel" Journal of Materials Processing Technology 148 (2004) 362-367.

[10]. Brajesh Kumar Lodhi, Sanjay Agarwal "Optimization of machining parameters in WEDM of AISI D3 Steel using Taguchi Technique', 6th CIRP International Conference on High Performance Cutting, HPC2014 Procedia CIRP 14 (2014) 194 - 199.

[11]. G.Selvakumar, G.Sornalatha, S.Sarkar, S.Mitra "Experimental investigation and multi- objective optimization of wire electrical discharge machining (WEDM) of 5083 aluminum alloy" Trans. Nonferrous Met. Soc. China 24(2014) 373-379

[12]. A book of Modern Machining Processes "Thermal Removal Processes" By P.C Pandey \&H. S. Shan

[13]. Production Technology by P.C Sharma, Pg. 565572.

[14]. A book of Description and Development of Electrical Discharge Machining (EDM). Available on www.sme.org

\section{Cite this article as :}

Gajanan Kamble, Dr. N. Lakshamanaswamy, Gangadhara H S, Sharon Markus, N. Rajath, "A Study on Optimization of Process Parameters in Machining of Bronze using Wire-EDM", International Journal of Scientific Research in Science and Technology (IJSRST), Online ISSN : 2395-602X, Print ISSN : 2395-6011, Volume 8 Issue 5, pp. 484-493, SeptemberOctober 2021. Available at doi : $\quad$ https://doi.org/10.32628/IJSRST218562 Journal URL : https://ijsrst.com/IJSRST218562

\section{at}

